\title{
EVOLUÇÃO TEMPORAL DA QUALIDADE DA ÁGUA DO AÇUDE GAVIÃO/CE E SUA CORRELAÇÃO COM OUTROS FENÔMENOS
}

\author{
Ticiana Fontoura Vidal ${ }^{1}$
}

\author{
José Capelo Neto ${ }^{2}$
}

\begin{abstract}
RESUMO
Os reservatórios do Estado do Ceará, especificamente os localizados nos domínios das bacias metropolitanas, como é o caso do açude Gavião, são alvos de impactos resultantes de diversas atividades antrópicas desenvolvidas ao longo de suas bacias hidrográficas. $\mathrm{O}$ crescente aumento de algas nas águas é resultante de lançamentos contínuos de nutrientes, principalmente nitrogênio e fósforo, que modificam as características dos corpos d'água, bem como sua qualidade. Uma ferramenta importante para a definição de estratégias de recuperação, conservação e manejo de uma bacia hidrográfica é a determinação da carga de nutrientes, que tem a finalidade de avaliar o processo de eutrofização ao longo de um sistema. Para tal, foram analisadas amostras no ano de 2011 e reunidos dados históricos das séries nitrogenadas e fosfatadas de 2005 a 2010 do reservatório em estudo. Os resultados configuraram um processo de degradação ambiental, apresentando um quadro de eutrofização contínua e crescente, potencializado nos dois últimos anos, principalmente em relação as concentrações de amônia e fósforo total.
\end{abstract}

PALAVRAS-CHAVE: Série histórica. Qualidade de água. Eutrofização.

\section{TEMPORAL EVOLUTION OF WATER QUALITY IN THE GAVIÃO RESERVOIR AND ITS CORRELATION WITH OTHER PHENOMENA}

\author{
ABSTRACT \\ The reservoirs in the state of Ceará, specifically located in the metropolitan areas, such as the Gavião \\ Reservoir, are targets for impacts resulting from various anthropogenic activities throughout their \\ watersheds. The growing of algae in water is the result of continuous releases of nutrients, particularly

\footnotetext{
${ }^{1}$ Mestre em Eng. Civil (Saneamento Ambiental), Universidade Federal do Ceará/Aluna de Doutorado em Eng. Civil (Recursos Hídricos). ticianafvidal@yahoo.com.br

${ }^{2}$ Doutor em Eng. Civil (Recursos Hídricos), Universidade Federal do Ceará/Professor Adjunto. capelo@ufc.br
} 
nitrogen and phosphorus, which modify the characteristics of water bodies as well as their quality. An important tool for the definition of recovery strategies, conservation and management of a watershed is the determination of nutrient loading, which aims to evaluate the process of eutrophication along a system. In such way, samples were analyzed in the year 2011 and gathered historical nitrogen and phosphate series from 2005 to 2010 in the reservoir that is studying. The results have shaped a process of environmental degradation, presenting a framework for continuous and increasing eutrophication, potentiated the past two years, especially regarding the concentrations of ammonia and total phosphorus.

KEY-WORDS: Historical series. Water quality. Eutrophication process.

\section{EVOLUCIÓN TEMPORAL DE LA CALIDAD DEL AGUA DE LA PRESA GAVIÃO Y SU CORRELACIÓN CON OTROS FENÓMENOS}

\section{RESUMEN}

Los embalses en el estado de Ceará, específicamente localizada en las áreas metropolitanas de las cuencas, como la presa del Gavião, son objetivos para los impactos resultantes de diversas actividades antropogénicas en todo sus cuencas hidrográficas. El cultivo de algas en el agua es el resultado de las emisiones continuas de nutrientes, especialmente nitrógeno y fósforo, que modifican las características de las masas de agua, así como su calidad. Una herramienta importante para la definición de las estrategias de recuperación, conservación y gestión de una cuenca hidrográfica es la determinación de la carga de nutrientes, cuyo objetivo es evaluar el proceso de eutrofización a lo largo de un sistema. De la tal manera, se analizaron las muestras en el año 2011 y recogieron nitrógeno y fosforo histórico serie de 2005 a 2010 en el depósito que si está estudiando. Los resultados han dado forma a un proceso de degradación del medio ambiente, la presentación de un marco para la continua y creciente eutrofización, potenciada por los últimos dos años, especialmente en relación con las concentraciones de amoniaco y fósforo total.

PALABRAS-CLAVE: La serie histórica. Calidad del agua. Eutrofización.

\section{INTRODUÇÃO}

O crescimento demográfico e o aumento de atividades potencialmente impactantes em todo o mundo tornaram crescente a preocupação com a qualidade das águas. Todas as atividades impactantes são refletidas direta ou indiretamente na qualidade da água dos mananciais, razão pela qual, o monitoramento de variáveis bióticas e abióticas pode ser utilizado como eficiente ferramenta para se avaliar a extensão e a magnitude de cada atividade antrópica poluidora (COGERH, 2004). 
O fenômeno da eutrofização é um mecanismo desenvolvido sob a presença de uma grande carga orgânica proveniente de lançamentos de efluentes domésticos ou industriais, os quais transportam, para os reservatórios, grandes quantidades de nutrientes. Esse quadro é favorável à proliferação de grandes quantidades de diferentes espécies de algas e plantas aquáticas, às quais tornam essas águas com baixo padrão de qualidade.

Estes nutrientes provêm dos diferentes usos dos solos nas bacias hidrográficas e o aumento de sua concentração na água tem como consequência a perda da qualidade, especialmente pela promoção de florações expressivas de microalgas e macrófitas. $O$ lançamento excessivo de nutrientes nos ambientes modifica as características dos corpos d'água e afeta diversos usos que vão desde a preservação da vida aquática até o abastecimento público (OLIVEIRA et al., 2009).

Para avaliação do impacto da poluição e da eficácia das medidas de controle, é necessária a quantificação das cargas poluidoras afluentes ao corpo d'água. Para tanto, são necessários levantamentos de campo na área de estudo, incluindo amostragem dos poluentes, análises de laboratório, medição de vazões e outros.

A existência de séries históricas de dados e sua interpretação permitem uma melhor compreensão da evolução temporal da qualidade da água e sua correlação com outros fenômenos, indicando prioridades para a elaboração de ações de controle, que levem à proteção e/ou melhoria da qualidade ambiental. Com outras palavras, séries históricas podem ser analisadas a fim de se estabelecer padrões de distribuição sazonais e espaciais para indicadores bióticos e abióticos. O conhecimento destas variações pode ser manipulado e utilizado para a previsão da qualidade de água durante $\mathrm{O}$ ano hidrológico, além de subsidiar parâmetros de operação dos reservatórios (MACHADO et al., 2012).

Os dados da série histórica da qualidade de água no açude Gavião foram disponibilizados pela Companhia de Gestão dos Recursos Hídricos do Ceará (COGERH). Os parâmetros presentes nos dados históricos fornecidos foram: nitrito, nitrato, amônia, ortofosfato e fósforo total para os anos de 2005 a 2011. 


\section{DESENVOLVIMENTO}

\subsection{Metodologia}

Amostras de água foram coletadas no açude Gavião em cinco pontos distintos ao longo de campanhas com periodicidade mensal de janeiro a dezembro de 2011, compreendendo ciclos de estiagem e de chuva na região. A escolha de cada ponto a ser monitorado foi feita levando em consideração a importância estratégica de cada um em particular e sua localização dentro da bacia hidrográfica. As análises de nitrito, nitrato, amônia, ortofosfato e fósforo total foram determinados em laboratório, usando como referência Standard Methods for the Examination of Water and Waste water (APHA, 2005), sendo cada análise realizada em triplicata.

Juntamente com dados históricos, cedidos pela COGERH, uma evolução temporal pôde ser feita, sendo possível a comparação das concentrações encontradas no presente trabalho com dados anteriores para o mesmo reservatório. Os valores apresentados são médias simples anuais de todos os pontos amostrados para cada parâmetro.

\subsection{Resultados}

A Figura 1 mostra como o nitrito variou ao longo dos anos considerados neste trabalho.

Figura 1 - Variação da concentração de nitrito nos anos de 2005 a 2011 no açude Gavião/CE.

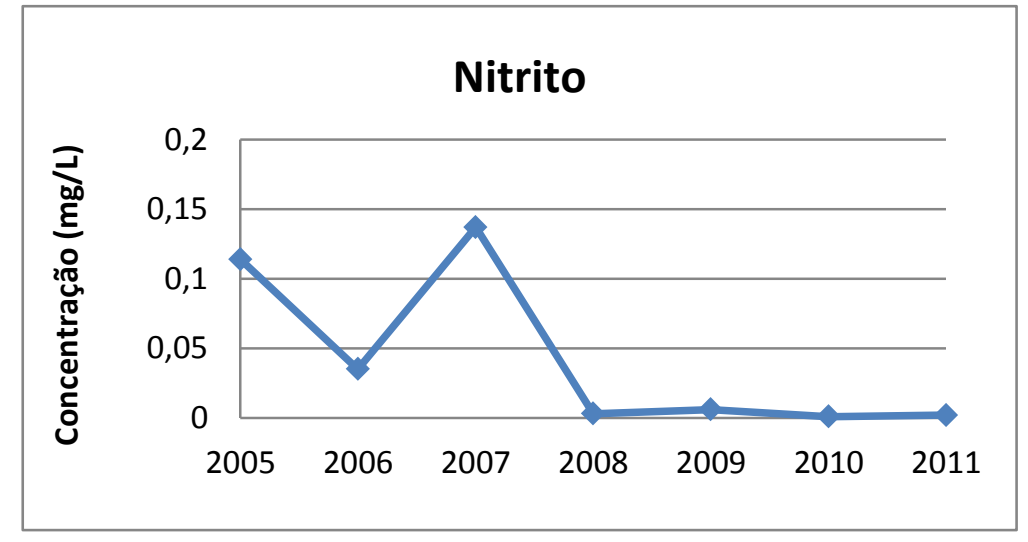


$\mathrm{O}$ nitrito $\left(\mathrm{NO}_{2}^{-}\right)$é um intermediário tanto no processo da nitrificação quanto no da desnitrificação. Em ambientes aquáticos tropicais com boa aeração, o processo de nitrificação ocorre de forma rápida. A concentração de nitrito, geralmente, é muito pequena e difícil de ser detectada (ESTEVES, 2011).

Os anos de 2005 e 2007 foram caracterizados por apresentarem os índices mais elevados na série histórica disponível, respectivamente 0,114 e 0,137 mg/L, já dos anos de 2008 a 2010 apresentaram concentrações mínimas de nitrito, com 0,003; 0,006 e $0,001 \mathrm{mg} / \mathrm{L}$, respectivamente. No ano de 2011 , as médias mensais para o nitrito apresentaram-se inferiores aos dados da série histórica, permanecendo abaixo dos $0,002 \mathrm{mg} / \mathrm{L}$. Desta forma, percebe-se que a partir do ano de 2008 até 2011, a concentração de nitrito nas águas do açude Gavião vem diminuindo em comparação ao pico máximo encontrado em 2007, não existindo grandes incrementos na concentração deste parâmetro na água ao longo dos últimos anos.

Geralmente, o nitrito está presente em quantidades mínimas em águas bem oxigenadas, pois é facilmente oxidado a nitrato, como acontece no açude Gavião. Estes resultados vão ao encontro daqueles observados por Hijo (2009), que em estudos no açude Castanhão/CE nos meses de novembro de 2006 a junho de 2007, observou que as concentrações de nitrito ficaram abaixo do limite de detecção em todas as campanhas e em todos os pontos de coleta estudados.

Os dados históricos para o nitrato no açude Gavião são mostrados na Figura 2, levando em conta todos os pontos amostrados e a série histórica.

Figura 2 - Variação da concentração de nitrato nos anos de 2005 a 2011 no açude Gavião/CE.

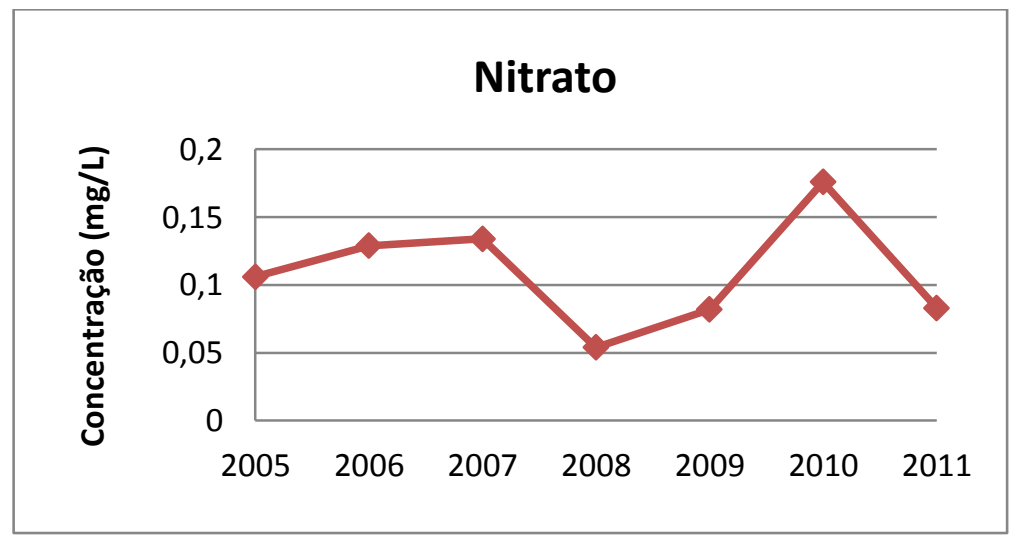


Dentre as formas de nitrogênio no ambiente aquático, o nitrato juntamente com o íon amônio são os mais importantes, já que são as fontes de nitrogênio mais facilmente assimiladas pelos produtores primários.

Durante o ano de 2010, observou-se o maior valor encontrado nos últimos anos, $0,176 \mathrm{mg} / \mathrm{L}$. No presente trabalho, referente ao ano de 2011 , a concentração média de nitrato foi de 0,083 , ligeiramente inferior ao ano anterior. $O$ menor valor encontrado até então foi equivalente ao ano de 2008, com 0,054 mg/L.

Luna (2008), em estudos no açude Acauã/PB, verificou concentração média de nitrato de 0,251 mg/L, com valores entre 0,009 e 0,0352 mg/L. $O$ autor observou que na extensão da zona fótica, as concentrações desta espécie eram maiores, devido a maior incidência de luz, onde há maior concentração de oxigênio, predominando a espécie mais oxidada, $\mathrm{NO}_{3}{ }^{-}$. O valor médio encontrado foi um pouco acima das médias observados no açude Gavião durante os anos aqui estudados.

Para a amônia, a série temporal é mostrada na Figura 3. A amônia é o produto inicial da decomposição de nitrogênio orgânico e está frequentemente presente como indicador desta decomposição recente ou em ambientes com baixo potencial redox ou ambientes anóxicos. $\mathrm{O}$ aumento de amônia pode resultar na mortandade de seres vivos aquáticos, por ser um componente químico altamente tóxico à vida.

Figura 3 - Variação da concentração de amônia nos anos de 2005 a 2011 no açude Gavião/CE.

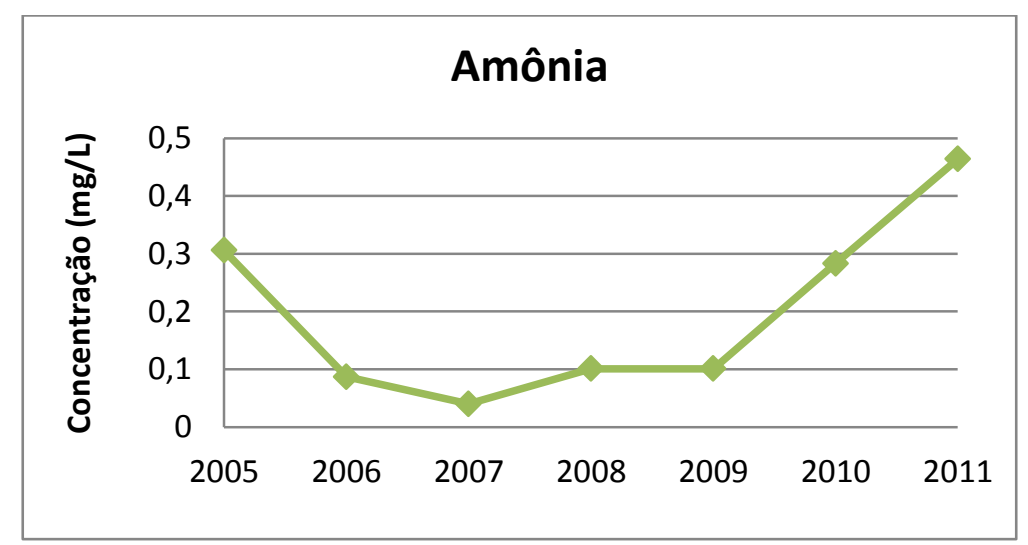


Observou-se que as concentrações permaneceram praticamente inalteradas entre 2006 e 2009, quando nos dois anos subsequentes encontrou-se maiores valores, 0,283 e $0,464 \mathrm{mg} / \mathrm{L}$ respectivamente.

Para o mesmo açude, Freire (2007) encontrou nos anos de 1998 e 1999 concentrações médias mínimas de $0,114 \mathrm{mg} / \mathrm{L}$ e máximas de $0,820 \mathrm{mg} / \mathrm{L}$ de amônia, sendo este valor máximo bem superior ao encontrado em 2011. Em geral, anos mais chuvosos apresentam teores de amônia mais elevados, decorrentes da maior entrada deste nutriente no açude pelas chuvas e da amonificação, formando amônia durante o processo de decomposição da matéria orgânica particulada e dissolvida em ambiente de baixo potencial redox.

O ortofosfato (Figura 4) apresentou-se em aproximada constância ao longo da série temporal, com valores entre 0,000 e $0,150 \mathrm{mg} / \mathrm{L}$.

Figura 4 - Variação da concentração de ortofosfato nos anos de 2005a 2011 no açude Gavião.

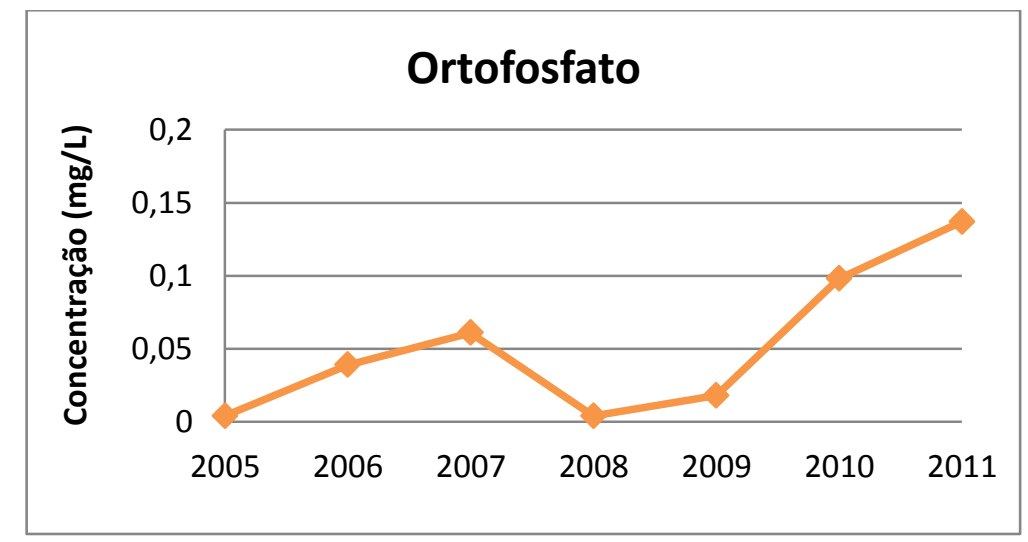

A presença de ortofosfato na água depende da quantidade e do metabolismo dos organismos aquáticos, principalmente os fitoplantônico e as macrófitas aquáticas. O metabolismo desses organismos aumenta consideravelmente em lagos tropicais (como é o caso do açude Gavião) devido à temperatura. Dessa forma, o ortofosfato é rapidamente assimilado durante a fotossíntese e incorporado à sua biomassa, fazendo com que sua concentração na coluna d'água seja baixa (Esteves, 2011).

As médias anuais seguem crescente de 2005 (0,004 mg/L) a $2007(0,061$ $\mathrm{mg} / \mathrm{L})$, já em 2008 (0,004 mg/L) houve uma diminuição da concentração de fósforo 
solúvel no açude Gavião e no ano seguinte, a concentração média já volta a aumentar, chegando em 2011 à uma concentração média de 0,137 mg/L.

Para o fósforo total (Figura 5), a concentração encontrada nos anos da série histórica foram bem inferiores a média atual de 0,802 mg/L de 2011 .

Figura 5 - Variação da concentração de fósforo total nos anos de 2005 a 2011 no açude Gavião/CE.

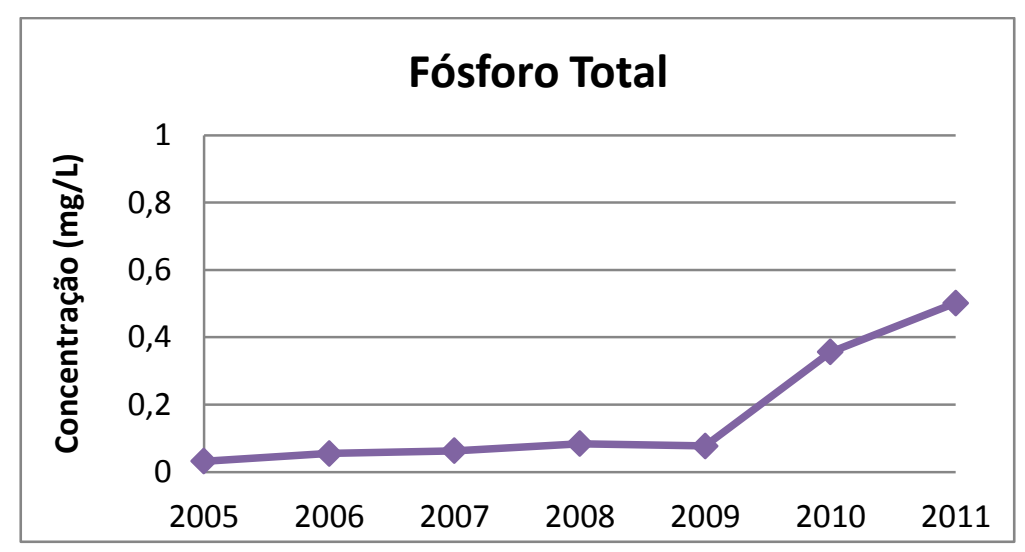

As concentrações dos últimos dois anos chegam a quase cinco vezes a encontrada nos anos anteriores, indicando um grande incremento de fósforo total a cada ano, contribuindo ainda mais para a deterioração da qualidade da água do açude. Os valores encontrados em 2010 e 2011 são bem acima das concentrações de fósforo total observadas na superfície da Lagoa do Batoque/CE, estudado por Oliveira (2006), que apresentou distribuição espacial média de 0,025 mg/L.

De acordo com a classificação de Salas \& Martino (2001), a concentração de fósforo total presente na água pode caracterizar os corpos hídricos tropicais em diferentes categorias tróficas (Tabela 1). 
Tabela 1 - Limites para classes de estado trófico

\begin{tabular}{c|c}
\hline CATEGORIAS TRÓFICAS & $\mathbf{P T}^{*}(\boldsymbol{\mu g} / \mathbf{L})$ \\
\hline Oligotrófico & $\leq 28$ \\
\hline Mesotrófico & $28-72$ \\
\hline Eutrófico & $\geq 72$
\end{tabular}

*PT = média anual da concentração de fósforo total. Fonte: SALAS e MARTINO (2001).

Sendo a concentração média de fósforo obtida com o atual trabalho 0,502 $\mathrm{mg} / \mathrm{L}$, pode-se classificar o reservatório Gavião como eutrofizado, por sua média da concentração de fósforo total apresentar-se bem superior ao limite de $72 \mu \mathrm{g} / \mathrm{L}$ estabelecido pelos autores supracitados.

É válido ressaltar, que o açude Gavião é responsável pelo abastecimento da Estação de Tratamento de Água (ETA-Gavião) que trata a água bruta e disponibiliza água potável para toda a região metropolitana de Fortaleza. Sendo assim, modificações na qualidade da água deste reservatório pode comprometer a tecnologia utilizada para o tratamento de água.

\section{CONCLUSÃO}

Comparando-se os resultados obtidos (2011) com a série histórica disponibilizada pela COGERH para os anos de 2005 a 2010, observou-se uma situação de crescente aumento das concentrações dos parâmetros estudados, principalmente amônia e fósforo total, nas quais as médias apresentaram-se nitidamente superiores às médias históricas, indicando um alerta, para que sejam realizadas medidas preventivas/corretivas, a fim de que não sejam necessárias medidas repadoras mais onerosas, pois como já se sabe, o açude Gavião é responsável por alimentar a estação de tratamento de água e esta por sua vez, tem por responsabilidade abastecer toda a região metropolitana de Fortaleza com água potável. Desta forma, significativas modificações na qualidade da água, principalmente devido à presença excessiva de algas, podem acarretar dificuldades 
no tratamento da água, comprometendo a tecnologia utilizada na estação e também possíveis problemas de saúde pública, devido à toxicidade de algumas algas.

\section{REFERÊNCIAS}

APHA - American Public Health Association. Standard methods for the examination of water and wastewater. 21.ed. Washington: APHA, 2005. 1207p.

CEARÁ. Companhia de Gestão dos Recursos Hídricos. Rede de monitoramento de qualidade de água para o gerenciamento dos recursos hídricos. Fortaleza, 2004.

ESTEVES, F. A. Fundamentos de limnologia. Rio de Janeiro: Interciência /FINEP, 2011. 790p.

FREIRE, R. H. F. Contribuição ao conhecimento limnológico de reservatórios do semiárido brasileiro que abastecem a Região Metropolitana de Fortaleza: açudes Pacajus e Gavião (Ceará, Brasil). Tese de Doutorado em Engenharia Civil, Escola de Engenharia de São Carlos, Universidade de São Paulo, 2007.

HIJO, C. A. G. Quantificação do efeito do açude Castanhão sobre o fluxo fluvial de material particulado em suspensão e nutrientes para o estuário do rio Jaguaribe, Ceará - Brasil. Dissertação de Mestrado em Ciências Marinhas Tropicais, Instituto Ciências do Mar, Universidade Federal do Ceará, Fortaleza, 2009.

LUNA, B. J. C. Características espaço-temporais do sistema do açude Acauã-PB e seu atual índice de estado trófico. Dissertação de Mestrado em Desenvolvimento e Meio Ambiente, Programa Regional de Pós-Graduação em Desenvolvimento e Meio Ambiente, Universidade Federal da Paraíba, Campina Grande, 2008.

MACHADO, E. C. M. N.; GALVÃO, C. O. ; SOUZA FILHO, F. A. Alocação quali-quantitativa da alocação de água em bacias hidrográficas: Metologia multiobjetiva inserida no contexto de recursos hídricos. Revista Brasileira de Recursos Hídricos, v.17, p.213-228, 2012.

OLIVEIRA, E. C. Aspectos limnológicos e sanitários de uma lagoa costeira no litoral leste do Ceará - Lagoa do Batoque. Dissertação de Mestrado em Hidráulica e Saneamento, Escola de Engenharia de São Carlos, Universidade de São Paulo, 2006.

OLIVEIRA, T. M. B. F.; DI SOUZA, L.; CASTRO, S. S. L. de. Dinâmica da série nitrogenada nas águas da Bacia Hidrográfica Apodi/Mossoró - RN - Brasil. Eclética Química, v.34, p.17-26, 2009.

SALAS, H. J; MARTINO, P. Metodologias simplicadas para la evaluación de eutroficación en lagos cálidos tropicales. Programa Regional CEPIS/HPE/IOPS, Versão revisada, 2001, 52p. 